\title{
Partial Immunities: Rethinking Communities and Belonging through Viral Memories of Influenza
}

\author{
Venla Oikkonen ${ }^{1 *}$
}

Published: September 27, 2018

\begin{abstract}
The article explores the concept of partial immunities - our past infections providing partial protection against new related epidemics - in order to develop feminist tools for rethinking communities and belonging as situated and inherently multiple. Partial immunities challenge the idea of immunity as defence/defeat and absence/presence, allowing us to approach immunity as never fully achieved and as arising from historical coincidence rather than personal strength. The article investigates these issues through influenza. It argues that partial immunities to influenza highlight the historical layering of communal ties and interspecies entanglements. The concept of partial immunities enables us to conceptualise belonging as multiple, constantly changing, and technologically enacted. The article develops this argument through two analyses, one focusing on current attempts to create a universal influenza vaccine and one centring on the ways in which past epidemics enact invisible immunological communities across time and space.
\end{abstract}

Keywords: community, immunity, influenza, intersectionality, vaccines

\section{INTRODUCTION}

The concept of immunity has played a central role in analyses of biomedical, social and political developments during the past decades. The rise of HIV and AIDS in the 1980s brought immunity into a public and scientific spotlight and posited it as an urgent biomedical question (Martin, 1994; Treichler, 1999). Embodied phenomena such as pregnancy, and practices such as organ and tissue transplantation, have shed light on the complexities of immunity by demonstrating how a lack of immune response to 'foreign' biological material - immunological tolerance - is sometimes crucial for the preservation of life (e.g. Takeshita, 2017). Furthermore, a growing understanding of autoimmunity as underlying a range of diseases such as type 1 diabetes, multiple sclerosis, celiac disease, rheumatoid arthritis and narcolepsy, has problematised the assumption that the immune system automatically recognises and defends against foreign biological material. Research has also shown that some level of autoimmune response is part of 'healthy' biological processes. (For an overview of these biomedical developments, see Mutsaers, 2016, 43-56.)

At the same time, scholars have argued that the logic of immunity structures how contemporary societies operate (see Mutsaers, 2016). For example, in his book Immunitas, Roberto Esposito identifies an immunitary paradigm' (Esposito 2011: 7) that encompasses diverse societal developments including state control over migration, the invocation and management of terrorist threats, and the preparedness for emerging infectious diseases. Apart from characterising a current state of social and political life, the concept of immunity has also operated as a theoretical tool through which scholars interrogate and conceptualise communities and their embodied and political entanglements (Cohen, 2009; Esposito, 2011; Mutsaers, 2016). Such work has also included alternative conceptualisations of immunity, as in feminist and anti-racist revisions of immunity and bodily boundaries as always porous and blurry (Haraway, 1991; Armstrong, 2017).

This article starts with the premise that immunity is of interest to both feminist scholars and scholars in medical humanities because it is an embodied phenomenon deeply entangled with both biomedical and societal discourse and practices. Understanding the multiple, overlapping and situated aspects of immunity requires critical engagement that, following Des Fitzgerald and Felicity Callard's (2016) suggestion, will not integrate a medical humanities viewpoint into a medical one, but takes the inseparability and entanglement of medicine, science, culture, and society as its starting point. The article participates in the longstanding feminist project of rethinking 
biomedical and political concepts - here, immunity - in ways that enable ethically accountable and situated visions of communality, power relations and social development. It seeks to open new ways of thinking how we as embodied beings belong (and do not belong) to the human and more-than-human worlds globally, locally, as well as across past and future generations.

The article theorises embodied belonging and connectedness through partial immunities. Put simply, partial immunities refer to how past infections protect us partially but not completely against new viral and microbial strains. It is a phenomenon recognised and analysed by scientists (e.g. Gomes et al., 2004; Katriel, 2010; Zhang et al., 2010), but one that lacks theoretical development as an embodied socio-cultural phenomenon. I propose that what makes partial immunity particularly interesting for feminist and other critical scholars is how it traces the incompleteness and temporal layering of our embodied social relations. For medical humanities research, partial immunity offers a way of thinking illness and health as overlapping and historically moulded dynamic processes. The article asks what kinds of embodied connections and shifting communities of future and past health and illness may emerge if we think of biomedical immunity as partial, and never quite complete. My point is not to posit partial immunity as a 'truth' about our embodied connectedness, or as an epistemically superior model of understanding processes of immunological protection and vulnerability. The article posits partial immunity simply as a fruitful way of imagining embodiment in times of health and illness because it allows us to rethink our bodies and communities in ways that highlight connections rather than boundaries. Perhaps most importantly, it enables multiple, parallel belonging; this is why I use the plural form immunities. Conceptualised as partial and situated, immunities emerge as ways of crafting connections across time and space in multiple directions.

I want to emphasise that partial immunities do not constitute a reality that pre-exists its study. Rather, partial immunities are enacted through particular technological and material practices in immunology as well as specific ways of theorising belonging, collective memory and intersectionality. The article draws here on Fitzgerald and Callard's (2016) use of Karen Barad's (2007) term agential cut, which refers to the enacted nature of phenomena: boundaries around and within phenomena emerge through the technologies, practices and discourses through which phenomena are studied. Fitzgerald and Callard note that both medicine and life itself are constituted precisely through relations, and through practices of bordering, cutting and exchange through which those relations come to matter' (Fitzgerald and Callard, 2016: 44). Thus, they argue, medical humanities scholars need 'to understand how practices of making, breaking and shifting boundaries constitute illness and healing' (Fitzgerald and Callard, 2016: 42). My theorisation of partial immunities emerges from acts of highlighting certain technologies over others and of manipulating perspective, the angle from which phenomena are approached. At the same time, the ways in which the article's approach departs from previous theorisation of immunity in feminist theory, medical humanities as well as political theory render visible the equally enacted and situated nature of these other approaches to immunity.

The approach developed in this article builds on the extensive literature on immunity that highlights connections between biomedical, social and political aspects of immunity. A large part of existing literature approaches the connection between immunity and community in the context of political theory and philosophy (Esposito, 2011; Fishel, 2017; Mutsaers, 2016). The connection between biomedical immunity and political community has been approached as a historically shaped object in cultural history of science and biomedicine (Cohen, 2009). It has also been theorised as a biomedical phenomenon that undermines bodily and communal boundaries (Fishel, 2017; Newman et al., 2016). While these approaches differ considerably, they typically conceptualise immunity as an impossibility. That is, immunity is an illusion as a political project (building impenetrable national boundaries), social policy (disconnecting infected individuals and communities from the healthy), as well as a biomedical process (protecting the body from its microbial and pathogenic environment). This article departs from the logic of immunological failure and success that much of the previous scholarship traces. I approach immunity as neither a matter of failure (falling national, communal and bodily boundaries) or success (for example, gaining immunological protection through openness to the microbial world). However, this departure from previous literature is not a matter of disagreement or critique, but rather a different way of imagining immunity in which failure and success disappear from the analytical focus. Furthermore, the article focuses on cultural theorisation of communities as ambivalent networks of future-oriented potentiality and pastoriented communal memory rather than political entities. The article approaches communities as situated formations emerging through belonging, temporality and space. Its approach to community and immunity draws on the theorisation of time, space and memory in cultural studies, and the analysis of the situatedness of technologies in feminist science and technology studies.

The article theorises partial immunities through an illness that is common yet dramatic in scale: influenza. As a seasonal, repeated illness, influenza shapes and reshapes our immune systems throughout our lives, and is constitutive of what we are immunologically and communally in our everyday encounters. As a rapidly mutating virus (with multiple, unstable strains), influenza illustrates the temporal and spatial limits of immunity as well as points to the volatility of material relationships between us and the microbial and viral worlds. The article begins 
with a discussion of the concept of immunity in previous research, which is followed by two analytical sections. The first section explores the future-orientation of partial immunities through the question of viral mutation and drift, using influenza vaccines as an example. Influenza vaccines are based on forward-looking speculative evaluation as to which strains may circulate each year, and consequently an influenza vaccine is often close enough to provide some but not full protection against circulating viral strains. I focus on recent attempts to develop a universal influenza vaccine that would cover a large number of strains, and thereby replace situated partial immunities with lasting immunity. While lasting immunity through a universal influenza vaccine might in reality provide only partial protection, it would refashion the temporality of communal ties enacted through influenza epidemics and pandemics.

The second analytical section examines the past-oriented underpinnings of partial immunities through the idea of viral memory. Viral memory refers to how previous influenza epidemics leave traces in our immune systems that archive the past. I outline how viral memories live not only inside each of us but also around us - in other people, in other species (pigs, birds), as well as in viruses themselves. Viral memories enact viral communities both socially and immunologically by crafting connections between organisms (people, species) across time and space through their shared entanglement in past epidemics. Crucially, viral memories render visible how viral communities are plural and overlapping at any moment in time. This spatial and temporal multiplicity of viral communities challenges the idea of embodied immunity as a stable and clearly defined state. The article will conclude with a brief reflection on the implications of partial immunities for feminist theorisation of bodies and boundaries, on the one hand, and medical practice and global health, on the other.

\section{CONCEPTUALISATIONS AND CRITIQUES OF IMMUNITY}

This section will take a closer look at four central themes in critical social and cultural theorisation on immunity. The first theme centres on the relationship between the biological body and the body politic. It has been addressed by Ed Cohen (2009), Roberto Esposito (2011), Stephanie Fishel (2017) and Inge Mutsaers (2016) among others. As Esposito (2011) points out, the concept of immunity - immunitas - was a legal and political concept in ancient Rome, indicating exemption from communal duties, and it has moved from there to describe the larger body politic, and, especially during the nineteenth century, the health and illness of the human body. With the increasing acceptance of germ theory after 1850 and the introduction of the science of immunology in the 1880s, the concept of immunity was invoked to indicate the ways organisms defend against pathogens. Yet the connection to the body politic remained. For example, biopolitics involves managing populations through questions of biomedical life, death and reproduction on the level of individual organisms (e.g. Cohen, 2009).

Biological immunity operates as a metaphor for the health of the body politic in at least two ways. First, the metaphor places emphasis on the borders of the nation, which are assumed to be constantly threatened by foreign forces or immigration, just like the boundaries of the body have been understood to protect us from contagion. Immunity stands for the protection and maintenance of the borders of the nation. Second, it highlights social coherence. In this framework, physical illness - failure of immunity - stands for perceived social illness, such as 'unhealthy' social movements seeking to unsettle the political status quo. This metaphorical connection works also the other way, so that physical illness (failure of the immune system) can be attributed to political and social ills such as socialist, feminist or anti-colonialist sympathies and activities. Crucially, both the insistence on national borders and the insistence on social coherence posit immunity as an urgent political goal. Yet the constant failures of immunity that haunt both national coherence and management of borders suggest that immunity relies on inherent impossibility.

The second theme is the militarist discursive framing of the immune system. This theme is connected to the question of the body politic, as the need to protect the immunity of the nation is typically conceived as a military operation or constant semi-military surveillance. Feminist scholars have provided particularly poignant critiques of militarist discourse. In her famous essay The Biopolitics of Postmodern Bodies: Constitutions of Self in Immune System Discourse, Donna Haraway (1991: 203-230) challenges the militarist imaginaries of attack and defence that underlie ideas of healthy immune system. By turning to science fiction - Octavia Butler's Clay's Ark (1984) and Dawn (1987) - she outlines alternative ways of conceptualising immunity as tolerance to foreign (other species) and subsequently the crumbling of firm boundaries between sameness and difference. Crucially, Haraway's (and Butler's) account of immunological tolerance is not an idealised account of happy coexistence, but a story of survival through compromise played out inside and around the most intimate, the gendered body.

In her book Flexible Bodies, Emily Martin (1994) explores how a wide range of people from doctors to practitioners of alternative medicine to patients and activists conceptualise the immune system. She shows how military discourse proliferates in media representations, yet the people interviewed understand the immune system in more ambiguous ways. They often highlight the flexibility of the immune system while understanding flexibility through a rhetoric of evolutionary fitness and competition. Furthermore, feminist scholars have unpacked the 
militarist logic of protecting the nation from epidemics perceived as foreign. In her book Contagious: Cultures, Carriers, and the Outbreak Narrative, Priscilla Wald (2008) traces how epidemics are managed by controlling national borders - both concrete borders involved in immigration and the coherence of the body politic - and how such acts of management take place through erasure of difference. Wald shows how gender, sexuality and race are associated with foreign contagion and are thus perceived as constituting a threat to the immunological health of the nation from early twentieth-century typhoid epidemics to late-twentieth and early-twenty-first century HIV, SARS and Ebola. She also highlights that immunity is always illusionary, as the very idea of community is based on contact between human beings.

The third theme centres on ableist assumptions about immunity. Immunity is typically conceptualised as a sign of strength, a person resisting the forces of the surrounding pathogenic world. Martin's (1994) analysis of the rhetoric of flexibility problematises the framing of flexibility as a strength. She shows how the flexibility of the immune system is sometimes seen as indicating evolutionary fitness (good genes), and sometimes seen as a learned skill, something a person may cultivate and practice - people she and her team interviewed talk about 'educating' the immune system (Martin, 1994: 229-250). In both cases, those who do not demonstrate strength by resisting illness appear as failing. Since biomedical immunity and the body politic are historically linked, failure to resist germs easily appears as a failure to be a responsible citizen. Such ableist logic underlies, for example, cultural representations of HIV and AIDS. As Paula Treichler shows (1999), vulnerabilities to HIV and AIDS were conceptualised throughout the 1980s and early 1990s through moral discourses of sexuality, gender, race and good citizenship. As a result, some people appeared as naturally susceptible to the deadly epidemic through their perceived moral failings, while others were falsely and dangerously seen as naturally immune to HIV. This indicates that assumptions of immunity and flexibility are not only assigned to the biological processes within the body but also extend to the psychic life of the citizen or the immigrant.

The fourth theme is the challenging of the distinction between self and other in immunitary discourse, and the fundamental blurriness of organisms. The focus here is on biomedical aspects of our existence, and in particular, how our health relies on cooperation with symbiotic species such as gut and skin bacteria. For example, Myra Hird (2009) shows how we have evolved with bacteria over millennia, and how it is impossible to establish where the human ends and other species begin. Chikako Takeshita and Stefanie Fishel have developed similar arguments, respectively, in relation to the entanglement of mother and foetus in pregnancy (Takeshita, 2017) and the rethinking of states through microbial life (Fishel, 2017). If human and nonhuman life are ontologically inseparable, then immune systems need to be able to deal with inseparability that does not fall within the traditional immunological framework of self and nonself. However, this ontological point applies also to microbes that may be harmful. In their study of MRSA epidemics, Joshua Newman, Rachel Shields and Christopher McLeod (2016) point out how paradoxically the very places that are made to boost our immunities - gyms, team sports facilities - are precisely the places where bodies and bodily fluids are most likely to come into contact and phenomena such as MRSA epidemics appear. They point out that communality is about contact and thus about contagion, and that bodies are blurry and leak into one another in ways that simply cannot be fully controlled. Furthermore, the question of immunity emerges as entangled with epigenetics, that is, how the effects of our exposure to environment including the microbial and viral worlds - are passed to next generations through human reproduction. However, as Maurizio Meloni (2018) points out, this is not simply an outcome of recent interest in epigenetics: ideas of blurry bodily boundaries and environmental effects on reproductive futures have played a central role in medical thinking since antiquity. Finally, even within contemporary medicine, immunity itself is an umbrella term that covers a wide range of biochemical and interspecies processes with very different temporal and spatial dynamics and health outcomes.

The article's discussion of partial immunities draws on these analyses by viewing humans as fundamentally entangled with other life forms - viruses, bacteria, other species. It assumes that seeking existence that is separate from other life forms is both impossible and pointless, as our entanglements with other species, organisms and 'animacies' (Chen, 2012) - things that are not quite alive, such as viruses or toxins - is what enables our being. At the same time, the analysis draws on the understanding of personal immunity as entangled with communal immunities, an entanglement that is both metaphorical and biomedical. In particular, I am interested in tracing immunitary connections that span time and space and that are unexpected, shifting and invisible to the eye.

Finally, this reading of partial immunities differs in crucial ways from the idea of flexibility critiqued by Martin. Both immunological flexibility and partial immunities are about negotiating our existence in an ever-changing microbial and viral environment, in which the need to adjust to new pathogens acts as a productive force. However, whereas flexibility highlights strength, signifying an attempt to master immunity despite the changing environment, partial immunities put emphasis on incompleteness as a normal state of our existence. Also, partial immunities emphasise the role of historical coincidence rather than individual ability in how our immunities have developed (and failed to develop) during our lives. In this, partial immunities emerge as a lens through which we can rethink 
immunitary communities not as entities but as temporally and spatially shaped situated affinities. Partial immunities are about belonging, but with a twist of historical coincidence.

\section{PARTIAL IMMUNITIES AND THE DREAM OF A UNIVERSAL INFLUENZA VACCINE}

The first approved influenza vaccine was developed and tested in the United States during the Second World War by a team that included Tommy Francis, Jonas Salk, and other prominent influenza and vaccine researchers. The vaccine was part of a war effort. As the 1918-1919 'Spanish Flu' pandemic had killed and hospitalized troops, the U.S. military wanted to prevent a similar pandemic (Dehner, 2012: 68-69). The vaccine was licenced for military use in 1945 and civilian use in 1946. The newly licenced vaccine provided protection during the 1946 influenza season, but the 1947 influenza epidemic made it clear that the vaccine, which had seemed so promising compared to some of the proposed influenza vaccines during the previous decades, had stopped working (Dehner, 2012: 6869). Researchers concluded that if the virus strain underwent antigenic shift (it mutated by recombining with another virus strain) or a different strain became prevalent, a new vaccine was needed.

Since these early years of influenza vaccination, scientists and the pharmaceutical industry have continued to seek better influenza vaccines. Such attempts constitute a future-oriented endeavour that seeks to manage the unknowable yet inevitable pandemic future through better prediction and biotechnological development. Yet, despite extensive research conducted on influenza viruses, influenza vaccines still need to be updated every year to reflect the virus strains that are expected to circulate that year. Seasonal influenza vaccines have been shown to benefit those with higher risk for complications - children, the elderly, pregnant women, people with chronic conditions. However, they produce an adequate immune response in a lower percentage of the people vaccinated than, for example, childhood immunisations against measles, which engender high levels of immunity (CDC 2017; Deng et al., 2018; Du et al., 2018).

The case of influenza vaccines makes visible the logic of partial immunities. Here the question is not about naturally occurring immunity - I will return to that in the next section - but of partial immunities produced through biotechnology: a vaccine. The development of a seasonal influenza vaccine each year begins with a decision, made by WHO experts twice a year (once for each hemisphere), on which strains to include in the vaccine. This decision is based on careful estimates of what will be the prominent strains during the forthcoming year. Sometimes these educated guesses prove partly wrong, and instead another strain becomes prevalent, or the virus mutates before the new season and thus the immune response following vaccination is weaker. In these cases, the vaccine often produces partial immunities - also known as cross-protection - making the symptoms of influenza less severe while failing to prevent illness.

In the past ten years in particular, there has been increasing interest in the prospect of developing a universal influenza vaccine, that is, a vaccine that would provide immunity even when the seasonal virus mutates or a new pandemic strain emerges. As one news story puts it, it is 'the holy grail' of influenza research (Branswell 2018). During the past couple of years, this interest has intensified. For example, in early 2018, the National Institutes of Allergy and Infectious Diseases (NIAID) in the United States published a strategic plan for creating a universal influenza vaccine (Erbelding et al., 2018). In the United Kingdom, a company called Vaccitech, an Oxford University spin-off, has currently a universal influenza vaccine in phase 2 clinical trial, meaning it is being tested on humans. Likewise, a universal influenza vaccine called M-001, designed by an Israeli company called BiondVax partnering with the NIAID, is in the phase 2 trial stage in the United States. Furthermore, at least two collaborative research projects, one based at Georgia State University and another involving several U.S. and Chinese institutions, have developed potential models for a universal influenza vaccine, reporting their results, respectively, in Nature Communications (Deng et al., 2018) and Science (Du et al., 2018). While these visions and experiments rely on different technologies and methods, they often target the stem of the influenza haemagglutinin (HA) located on the surface of the virus. Existing seasonal influenza vaccines target the HA head, which is precisely where most of the changes take place. The stem, on the other hand, is more stable and changes slower. For this reason, an immune reaction against the stem seems more likely to provide a basis for a vaccine that does not have to be changed every year.

It is interesting that the term universal in vaccine development is far from stable. Reports on the attempts to develop a universal influenza vaccine make it clear that it is unlikely that 'universal' will mean permanent. Many of the people interviewed for the media suggest that the goal is that the vaccine would not have to be administered annually but instead every few years. The chief executive of Vaccitech, for example, talks about 2-4-year coverage (Hirschler, 2017). Also, the vaccine would not protect against all possible strains of influenza but a limited (albeit large) number of strains (see Branswell, 2018). This illustrates that universality (in the sense of complete coverage and protection) remains unachievable even in the current attempts to provide lasting protection. While relatively long-lasting protection against a large number of changing strains would be a major biomedical achievement, it still posits immunity as partial and situated. In this sense, a truly universal influenza vaccine is indeed the Holy Grail.

(C) 2018 by Author/s 
Tellingly, many of the proposed vaccines are envisioned to be used not instead of the seasonal influenza vaccine but in addition to it.

Partial immunity in the case of vaccine development is a technologically enacted and temporally organised phenomenon. In this, it differs somewhat from the blurriness of immunological relationships resulting from the entanglement of human and nonhuman bodies discussed by scholars like Fishel (2017), Takeshika (2017) and Armstrong (2017), and introduced above. By technologically enacted I mean that vaccine technologies are inseparable from the immunological effects they have. That is, partial immunities exist only in relation to and through the technologies that produce and manage them. This is not a linear causal relationship: technologies and immunities co-produce one another. This kind of ontological co-production has been studied and theorised extensively within science and technology studies (e.g. Barad, 2007; Mol, 2002; see also Fitzgerald and Callard, 2016). For example, through the development of specific technologies that target particular sections of the stem of the viral haemagglutinin, vaccine technologies engender immunities to certain virus strains but not others. Technologies also set the limits of when immunity becomes partial immunity and when partial immunity disappears, as the reference to 2-4-year protection shows. At the same time, previous work to achieve immunities directs vaccine development, so that certain strains (close enough to the ones already covered) emerge as easier to immunise against than others. This temporal aspect is not specific to vaccine development: past biotechnological developments direct future research in science and medicine in general. Amade M'charek's (2014) analysis of genetic reference sequences as 'folded objects' produced through layered and accumulating histories of research illustrates this dynamic. While such objects may 'unfold' in new contexts and reveal their histories of making, those histories cannot be easily erased - they are part of the object itself.

By describing partial immunities in influenza vaccine development as temporally situated I mean that the temporality of the changing and mutating virus is entangled with the future-oriented temporality of biomedical research and vaccine development. Put simply, changes to the viruses 'out there' (outside the lab) direct what appears as a feasible next step in vaccine development. For example, the 2009 H1N1 (swine flu) pandemic and the several avian flu scares over the past twenty years have posited zoonosis - the crossing of new strains from nonhuman species to humans - as a source of pandemic strains, and thus as a key question for vaccine development. While the H1N1 pandemic turned out to be relatively mild and the avian flu scares have not materialised in a pandemic, the logic of pandemic preparedness - preparation for an unknown but inevitable future pandemic - has organised the goals of the development of a universal vaccine (see Caduff (2015) on the temporal dynamics of pandemic preparedness). In this sense, the oft-unpredictable temporalities of viral mutations - especially in the case of zoonotic viruses - structure the temporalities and imaginaries of vaccine research. At the same time, as Theresa MacPhail (2014) shows, the very organisation and infrastructures of virology and vaccine research shape the contours and travels of viruses (see also Ong, 2016: 174-196). Viruses are never simply natural objects that need to be managed. Attempts to manage them affect how they mutate and drift, and where and how they travel.

\section{VIRAL MEMORIES, TEMPORAL COMMUNITIES}

In his history of influenza in the twentieth century, George Dehner (2012) describes how scientists developed the so-called 'recycling theory' of influenza in the years following the 1957 Asian flu pandemic. According to this theory, influenza pandemics emerge at regular intervals - approximately every 11 years - an assumption that was soon proven wrong. The theory assumed that each new pandemic represents a new version of the influenza virus: only this way it can become pandemic, as enough people have not encountered it before, and are thus not immune. At the same time, each emerging pandemic virus is typically related to some earlier pandemic virus. This second conclusion was arrived at by studying antibodies to emerging pandemic viruses among different age groups. For example, in the case of the 1957 Asian flu, Dutch scientist J. Mulder found out that:

a surprising number in the elderly population (between seventy and eighty-four years of age) produced antibodies to the new influenza strain. ... Anyone seventy years old in 1957 would have been born in 1887, which suggests that the 1957 Asian flu was either the same as or very similar to the pandemic Russian flu of 1889. (Dehner, 2012: 96)

Likewise, based on a similar method of measuring antibodies in different demographic groups, researchers concluded that the 1968 Hong Kong flu was likely related to an influenza virus that circulated in 1900 (Dehner 2012: 97). Furthermore, Tommy Francis coined the concept of 'original antigenic sin' (now called imprinting) to capture how people developed partial immunities against influenza viruses (Dehner, 2012: 97). Francis suggested that our strongest immune response is to the first influenza virus we encounter in childhood. This 'original antigenic sin' was assumed to provide us with partial immunity against future variations of that same virus. 
This example suggests that partial immunity is a deeply historical and temporal phenomenon. In particular, it reveals a past-orientation that underlies partial immunities. Intriguingly, this past-orientation places partial immunities engendered through earlier influenza pandemics in tension with the future-orientation underlying influenza vaccine development explored above. Partial immunities accrued through our embodied experiences of previous pandemics locates us in time. They situate us in relation to historical events such as the movement of populations (and pandemic viruses) across continents and the gathering of large numbers of people in small quarters during the two World Wars. It connects us to the patterns of increasing travel (and subsequent accelerated speed of viral spread) towards the end of the twentieth century. The fast mutation rates of influenza viruses highlight this temporal dynamic. While many viruses are antigenically stable and go through only slow mutation, influenza is almost always different from its past materializations. This means that our immunities toward influenza viruses even in the case of viruses resembling older viruses - are inevitably partial at best.

One key consequence is that our immunological situatedness emerges as gradual and ontologically multiple. Rather than a matter of absence or presence of immunity to influenza in general, our bodies embody varying degrees of partial immunity towards different influenza viruses. This posits our immunities as organised through multiple temporalities between plural pasts and presents. Furthermore, partial immunities emerge as coincidental. That is, immunity is not primarily a matter of inherent strength or flexibility, but an outcome of our everyday locations and mobilities. These circumstances include, for example, whether particular epidemics reach the places where we live or work, and whether we become ill with a particular virus while travelling away from home. In this configuration, illness (and ensuing partial immunity to the virus) appears as an unexpected consequence of our actions or inaction. As, historically, most people have had relatively little control over where they live and travel and this is still the socioeconomic reality of the majority of the world - infections and immunities are not a matter of choice. Crucially, this attention to socioeconomic inequalities invests partial immunities with critical potential as a tool of feminist and postcolonial political imaginations.

The ways epidemics and pandemics travel also engender connections between people located at great distance, including different continents; in this sense, immunities are not only temporal but also spatial. People who seem to share very little culturally or socially, might still be connected through the embodied experience of illness such as the 1918-1919 pandemic influenza - even if these experiences are very different. People are connected through the material immunological processes taking place inside their bodies, and the antibodies they can produce quickly still decades after the illness. Crucially, such connections are invisible and thus largely socially insignificant - that is, they do not bring people in different cultures and continents any closer either socially or politically. To put it slightly differently, the concept of partial immunities does not seek to celebrate diversity while hiding inequalities. Rather, the invisible immunological connections outlined here provide a means of thinking about embodied belonging and communities as unexpected and always multiple. This is why such connections might be helpful for feminist theorists, medical humanities researchers, as well as medical practitioners.

Turning to a different field of technoscience - population genetics - will shed light on some aspects of these invisible connections. Population genetics is a field of science that traces genetic variation between and within populations. These differences in turn are used to reconstruct human evolutionary history and the divergence of different population groups in the past. Population genetics focuses on different types of genetic material, typically mitochondrial DNA (DNA located in the cytoplasm outside the cell nucleus) and nuclear DNA (DNA located in the chromosomes inside the cell nucleus). Likewise, population geneticists study different sets of genetic markers, use different samples or databases, and utilise different analytical software with different algorithms. Although population genetic technologies, such as commercial genetic ancestry tests sold online, often insist that population genetics can produce truths and certainties about our genetic roots, population genetic practices in fact engender a range of different roots depending on the above-described methodological choices and material conditions (see Hinterberger, 2012; M'charek, 2005; Nash, 2015; Oikkonen, 2018). Genetic kinship, that is, is technologically enacted and thus multiple. Most importantly for this discussion, what we look at and how we look at it determines what we find. This is also the point made by Fitzgerald and Callard (2016) in their exploration of critical medical humanities as fundamentally 'entangled' with medical practice, clinical research, and life itself.

In the case of partial immunities, how we look at temporally, geographically, and geopolitically situated histories of people structures what we see. If we focus on the level of antibodies to a particular new epidemic, that act of looking constructs connections between particular groups of people in different locations. As with population genetics, methods matter: since we cannot study all people of the world, what age groups and locations we include enacts previously invisible connections. By contrast, looking at different locations and demographic groups would engender different webs of immunological affinity and historical connection. Also, if we look at several different epidemics, the webs of immunological connection emerge as plural. We may belong to a web of connections and antibody affinities around one epidemic but not another, as different viruses have affected us differently, sometimes passing by us. This means that we are simultaneously part of multiple immunological webs of connection that may or may not be articulated when virus strains mutate and re-emerge in the future, or when 
influenza vaccines are developed. It is also important to recognise that there is another web of immunological connectedness - the people who did not survive; the webs of belonging enacted by focusing on partial immunities erase them from the view. With this limitation in mind, partial immunities may operate as a useful critical concept because it rejects the idea that clear boundaries can be drawn between who we are and who we are not, where we belong and where we don't belong, and instead insists that identities and affiliations are multiple, situated, and inherently ambiguous.

Looking at partial immunities as creating invisible webs of connection also draws attention to the embodied materiality of our immunological histories. On the one hand, the antibodies that we produce emerge as locations of viral memories. In this, they resemble the idea of our DNA as an archive or historical document common in discourses surrounding population genetics. On the other hand, viruses that re-emerge and circulate decade after decade are outcomes of processes of mutation and drift; such viral evolution in turn takes place through viruses' entangled interactions with their changing environments. Each virus carries memories of past epidemics and pandemics, which have shaped its form and pathogenic destiny. Since multiple variations of a virus exist in different locales, viral memories are complex and multiple, and typically mutually entangled. Viral memories are also productive, as suggested by recent research on how viral remnants shape protein evolution (e.g. Enard et al., 2016). In all these various materialisations of viral memory, the futures are shaped through memories of the past. The antibodies we produce, the viruses that re-emerge, and the protein structures shaped through viral entanglements all remember epidemic pasts in their own ways.

The core interest here lies in the metaphorical and conceptual potential of viral memory. While viruses or human bodies obviously do not remember anything, the assigning of memories to viruses and bodily processes parallels the cultural idea of DNA as connecting us to other people and places both past and present and thus as a means of collective memory (Oikkonen, 2018). The use of memory in relation to influenza viruses and epidemics draws attention to how traces of the past are stored in biological and material entities (antibodies, viruses, proteins), and how such material traces engender connections that tie the present to the events and places of the past. Intriguingly, such viral memories practically always transcend boundaries. Many people around the world are able to produce antibodies to re-emerging viruses thanks to epidemics they experienced earlier - that is, their bodies (and antibodies) remember the same events. Viruses, on the other hand, are shaped through their travels across the continents during epidemics or pandemics. They also circulate through the technoscientific infrastructures and networks of global health, which not only study them but also enact them, as noted above (MacPhail, 2014).

Furthermore, viruses transcend species boundaries, as most pandemic influenza viruses combine elements of human and swine or avian influenza strains - for example, the 1918-1919 'Spanish Flu' H1N1 pandemic virus included viral material from swine, avian and human strains. Influenza viruses manifest these histories of transcontinental and interspecies travel in their detailed structures, even when interspecies transmission is not a matter of a single event but 'repeated crossings, an ongoing conversation' between species, as Steve Hinchliffe (2015: 31) perceptively describes. Different entities (viruses, microbes, species) co-constitute one another in ways that cannot be fully untangled (Hird, 2009, 2013; Hustak and Myers, 2012; Landecker, 2016; Schrader, 2010). These processes of co-constitution are also often unexpected, forming what Eben Kirksey (2015) calls 'emergent ecologies', arrangements of life that emerge at sites where the conditions for living change suddenly. Crucially, this suggests that viral memory cannot be located in a single entity, but is multiple and diffused across networks of agents and ecologies. Viruses complicate such interspecies memory in specific ways. Requiring a host organism in order to thrive and multiply, viruses are neither living nor dead, but embody animacy or 'gradations of lifeness' (Chen, 2012: 167). As Mel Y. Chen's (2012) analysis of entities that are not quite alive shows, life and death constitute a productive non-binary dynamic. Approached from this angle, emerging pandemic viruses appear as entangled in complex dynamics of life, death and collective, materially dispersed memory that cannot be captured through the logic of absence/presence and victory/defeat.

\section{CONCLUSIONS AND FURTHER REFLECTIONS}

This article has revisited the concept of immunity central to current and emerging biomedical practices as well as social theorisation of contemporary culture. The concept of immunity is also a longstanding feminist concern as it structures our relationships to human and more-than-human others. The analysis has focused on the phenomenon of partial immunities because it departs from ideas of immunity as an absence or presence, as personal strength or immunological flexibility. The article has argued that influenza provides a useful viewpoint into partial immunities because influenza demonstrates that immunity may be a matter of degree rather than absence/presence both in future-oriented vaccine development and past-oriented viral memories. Moreover, the way in which our past influenza infections shape our potential partial immunities toward future influenza viruses suggests that partial immunities and immunological communities are temporally (historically) and spatially (geographically, socially) situated phenomena. 
Three aspects of partial immunities are particularly interesting from a feminist point of you. First, partial immunities highlight the incompleteness of our existence and actions. Rather than a matter of success or failure to protect oneself, partial immunities are about being always somewhere in-between, where failure and success appear as implausible concepts. Rather than valuating people as strong or weak, partial immunities acknowledge that our existence relies on incompleteness. In fact, sometimes incompleteness might be a good thing. As historians of science and scientists have pointed out, a striking feature of the 1918-19 Spanish Flu was how it killed young healthy adults. Research has shown that the immediate cause of death in these cases was often the patient's strong immune reaction, a so-called 'cytokine storm' in which

the immune system rushed an excessive amount of fluid and first-line immune-system defenders into the infected lungs, damaging not only virus-infected cells but also many cells surrounding the infected ones. (Dehner, 2012: 54)

Furthermore, partial immunities highlight coincidence: where we happen to be at a particular moment in time when epidemics spread to some places but not others shapes the immunological memories our bodies carry. At the same time, we are part of larger ecological systems, where viral memories extend beyond organisms and species.

Second, and following from the previous point, we could use the concept of partial immunities as a theoretical inspiration to rethink communities, ties and belonging from a feminist, intersectional, and posthumanist viewpoint. The focus falls on the blurriness of boundaries between species, places, nations and times. This does not mean that people connected through shared embodied viral memories across the world would be socially equal geopolitical power relations, colonial legacies and class structures play a crucial role in how people may protect themselves against epidemics through sanitation, access to healthcare, or availability of vaccines and antivirals. For example, if we consider vaccination campaigns against pandemic influenza, it is unrealistic that the whole population of the world could be vaccinated against a new pandemic within a few months; this became clear during the 2009 H1N1 (swine flu) pandemic, during which vaccines became available to those (relatively small and wealthy) countries who were already customers of big pharmaceutical companies and had secured a spot in the queue for the new pandemic vaccine. Likewise, relationships and entanglements between species are shaped by power. For example, the uses of nonhuman animals by humans in industrial-scale farming and food production reflect an ideology that views nonhuman species and natural environments as mere resources.

The concept of partial immunities does not need to be blind to these power hierarchies. Rather, showing unexpected connections between locations and people, or making visible the entanglements of species (humans, birds, pigs) and viruses in how epidemics and immunities emerge can draw attention to how hierarchies of power have become naturalised and entangled with biotechnologies and global health. Thereby the concept of partial immunities can highlight questions of social justice and posthuman ethics. If taken seriously, it could also provide a means of enacting collective historical experience - or lack of such experience - in ways that do not erase past and present power relations. In this sense, 'viral memory' could provide one starting point for intersectional and purposely ambiguous collective cultural memory. One crucial aspect of such cultural memory project is to recognise that collective memories are necessarily ontologically multiple. Just like the 'Spanish Flu' was lived and experienced differently by communities embedded differently in socioeconomic and postcolonial structures, there is no uniform embodied viral memory of the pandemic. The challenge, then, is how to imagine immunological connectedness without erasing multiplicity and difference. The article has argued that for feminisms committed to intersectional politics, this should not be seen as an obstacle but as an opportunity to understand embodied and lived complexities.

Third, the way in which immunological ties and viral communities emerge as multiple might be useful for feminist scholarship as a tool for rethinking our identities, affiliations and modes of belonging. The multiplicity of immunological ties outlined above emphasises the fundamental ambiguity of all forms of belonging. For example, we are situated quite differently in the evolving microbial world if we approach our situatedness in relation to measles or diphtheria (both diseases with effective and widely used vaccines) or human papillomavirus (sexually transmitted virus) instead of a particular strain of influenza. If we take this to the arena of feminist politics, we will need to acknowledge as a precondition of politics that the multiple and situated webs of ties and affinities we are part of can never be brought into harmony, and that the tensions that emerge between our multiple forms of belonging and affiliation could be seen as a resource for political activism that does not seek to harmonise. Just like collective memories can be mutually contradictory, our viral memories - always plural at any moment in time - constitute each of us as inherently ambiguous. This could provide an inspiration for a feminist politics based on ambiguity and multiplicity rather than coherence.

While the idea of the world as interconnected is nothing new, and underlies, for example, the so-called 'One Health' approach (see Hinchliffe, 2015), the concept of partial immunities provides a specific viewpoint into this interconnectedness. Whereas interconnectedness is typically conceptualised through migrations of people and animals, travels of goods and capital, or spread of technologies (such as the internet), partial immunities insist that 
people and species are connected without sharing anything visible or culturally recognisable. In this, the concept of partial immunities offers a view that reflects feminist analyses of invisible more-than-human flows involving, for example, leachate and geo-bacterial processes at landfill sites (Hird, 2013) or hormones circulating and accumulating in the environment (Roberts, 2007: 162-190). Just like these other flows and interactions, partial immunities shape us and our biomedical and social futures. What is specific to partial immunities, however, is how the concept of partial immunities places emphasis on temporal connections between past, present and future. As our past immunological histories shape our immunological responses to future epidemics, immunological communities are temporally organised, suggesting that it might be worthwhile to consider community as invisibly spanning time. Finally, the multiplicity of ties and communities is technologically enacted. Immunological ties and communities emerge through epidemiological studies of patterns of epidemic and pandemic spread, statistical studies of mortality and morbidity during an epidemic, and biomedical practices of measuring antibodies and other indicators of immunological response. If we move the concept of partial immunities to feminist politics and practice, this technoscientific enactment could help us pay attention to the ways in which our political affiliations and actions emerge from a range of naturalised, everyday technoscientific practices, and how a different set of technoscientific practices might render different affiliations and practices as politically meaningful.

The concept of partial immunities is also relevant for medical practice and global health. First of all, medical practice tends to conceptualise individuals through risk groups. For example, health care professionals are interested in a person's age, which might be associated with higher-than-average risk, or in a particular underlying condition that might increase their likelihood of becoming seriously ill from an infectious disease. Such models build on statistical analysis: identification of risk on population level. The population level operationalises categories of difference such as age (e.g. 20-40 years, over 65 years), and, depending on the disease, ethnicity, sexual activity and orientation, or gender. The individual patient is thus enacted as a member of one or several of these categorical groups. Such analysis of big data has undoubtedly a crucial role in epidemiological study and risk assessment. However, complementing it with an exploration of partial immunities would highlight the importance of paying attention to individual life narratives in assessing risk. The concept of partial immunities makes visible the intricacies and inconsistencies of individual lives and shows how our embodied immunities might sometimes place us in ways that cannot be captured by risk groups. This might be relevant, for example, for vaccination policies and campaigns, which typically operate on the level of demographic groups rather than individuals. The ways in which people are immunologically vulnerable or protected are often complicated and idiosyncratic. The concept of partial immunities might be helpful in making these idiosyncrasies visible, as the connections and immunities enacted through partial immunities are often invisible and sometimes unexpected.

A final issue to consider here is global health. As many scholars have pointed out (Caduff, 2015; Dehner, 2012; MacPhail, 2014), global health initiatives and practices are often structured on the nation as an underlying unit of epidemic preparedness and management. For example, as many have emphasised, the World Health Organization (WHO) is funded through nation-states, which have their own interests and views of what counts as public health risk or international health concern. For the most part, the WHO makes recommendations; decisions about pandemic vaccination campaigns, for example, are typically made on the national level. Also, data on epidemics is often collected through national infrastructures. It is precisely in this respect that the concept of partial immunities could open up ways of conceptualising connections and communities across geographic and temporal boundaries, and address public health issues through webs of embodied and situated immunities. However, such webs do not reflect a smoothly interconnected world, but one whose connections and apparent flows are technologically enacted and that is always ontologically multiple (see Hinchliffe, 2015). Furthermore, approaching such interconnections is not just a matter of thinking where partial immunities to new epidemics may be found - that is, which national or regional populations are 'safer' or 'riskier' than others - but of rethinking the logic of immunological connectedness and viral memories across spatial and temporal boundaries. While this is unlikely to have significant predictive value for public health professionals, it might help make visible omissions in existing nation-based models by showing, for example, how certain marginalised people within - and especially between nations-states might be simply invisible to nation-based approaches to global health and pandemic preparedness. Again, this highlights the importance of intersectionality. As partial immunities are always situated and incomplete, they reflect differences as embodied, historically shaped and politically claimed and contested realities.

\section{REFERENCES}

Armstrong, M. (2017). Germ Wars: The Politics of Microbes and America's Landscape of Fear. Oakland, CA: University of California Press. https:// doi.org/10.1525/california/9780520292765.001.0001

Barad, K. (2007). Meeting the Universe Halfway: Quantum Physics and the Entanglement of Matter and Meaning. Durbam: Duke University Press. https:/ / doi.org/10.1215/9780822388128 
Branswell, H. (2018). Despite push for a universal flu vaccine, the 'holy grail' stays out of reach. STAT (March 5). Available at: https://www.statnews.com/2018/03/05/universal-flu-vaccine-elusive

Caduff, C. (2015). The Pandemic Perbaps: Dramatic Events in a Public Culture of Danger. Oakland, CA: University of California Press.

CDC (Centers for Disease Control and Prevention). (2017). Vaccine effectiveness - how well does the flu vaccine work? Available at: https://www.cdc.gov/flu/about/qa/vaccineeffect.htm (Accessed 3 October 2017)

Chen, M. E. (2012). Animacies: Biopolitics, Racial Mattering, and Queer Affect. Durham: Duke University Press. https://doi.org/10.1215/9780822395447

Cohen, E. (2009). A Body Worth Defending: Immunity, Biopolitics, and the Apotheosis of the Modern Body. Durham: Duke University Press. https:// doi.org/10.1215/9780822391111

Dehner, G. (2012). Influenza: A Century of Science and Public Health Response. Pittsburgh: University of Pittsburgh Press. https://doi.org/10.2307/j.ctt6wrdfm

Deng, L., Mohan, T., Chang, T. Z., Gonzalez, G. X., Wang, Y., Kwon, Y.-M., Kang, S.-M., Compans, R. W., Champion, J. A. and Wang, B.-Z. (2018). Double-layered protein nanoparticles induce broad protection against divergent influenza A viruses. Nature Communications. https://doi.org/10.1038/s41467-017-02725-4

Du, Y., Xin L., Shi, Y., Zhang, T.-H., Wu, N. C., Dai, L., Gong, D., Brar, G., Shu, S., Luo, J., Reiley, W., Tseng, Y.-W., Bai, H., Wu, T.-T., Wang, J., Shu, Y. and Sun, R. (2018). Genome-wide identification of interferonsensitive mutations enables influenza vaccine design. Science, 359(6373), 290-296. https://doi.org/10.1126/science.aan8806

Enard, D., Cai, L., Gwennap, C. and Petrov, D. A. (2016). Viruses are a dominant driver of protein adaptation in mammals. eLife, 5, e12469. https:// doi.org/10.7554/eLife.12469

Erbelding, E. J., Post, D. J., Stemmy, E. J., Roberts, P. C., Deckhut, A., Ferguson, A. S., Paules, C. I., Graham, B. S. and Fauci, A. S. (2018). A Universal Influenza Vaccine: The Strategic Plan for the National Institute of Allergy and Infectious Diseases. The Journal of Infectious Diseases. https://doi.org/10.1093/infdis/jiy103

Esposito, R. (2011). Immunitas: The Protection and Negation of Life. Cambridge: Polity Press.

Fishel, S. R. (2017). The Microbial State: Global Thriving and the Body Politic. Minneapolis: University of Minnesota Press. https://doi.org/10.5749/j.ctt1pwt5z8

Fitzgerald, D. and Callard, F. (2016). Entangling the medical humanities, in A. Whitehead and A. Woods (with S. Atkinson, J. Macnaughton, J. Richards) (eds.) The Edinburgh Companion to the Critical Medical Humanities (pp. 3549). Edinburgh: Edinburgh University Press.

Gomes, M. G. M., White, L. J. and Medley, G. F. (2004). Infection, reinfection, and vaccination under suboptimal immune protection: epidemiological perspectives. Journal of Theoretical Biology, 228(4), 539-549. https://doi.org/10.1016/j.jtbi.2004.02.015

Haraway, D. J. (1991). Simians, Cyborgs, and Women: The Reinvention of Nature. London: Free Association Books.

Hinchliffe, S. (2015). More than one world, more than one health: Reconfiguring interspecies health. Social Science \& Medicine, 129, 28-35. https:// doi.org/10.1016/j.socscimed.2014.07.007

Hinterberger, A. (2012). Investing in life, investing in difference: nations, populations and genomes. Theory, Culture \& Society, 29(3), 72-93. https:/ / doi.org/10.1177/0263276411427409

Hird, M. J. (2009). The Origins of Sociable Life: Evolution after Science Studies. Basingstoke \& New York: Palgrave Macmillan. https://doi.org/10.1057/9780230242210

Hird, M. J. (2013). Waste, landfills, and an environmental ethic of vulnerability. Ethics \& the Environment, 18(1), 105-124. https://doi.org/10.2979/ethicsenviro.18.1.105

Hirschler, B. (2017). Oxford team to test universal flu vaccine in world first. Reuters. Available at: https://www.reuters.com/article/us-health-flu-vaccine/oxford-team-to-test-universal-flu-vaccine-in-worldfirst-idUSKCN1C80NI (Accessed 3 October 2017.)

Hustak, C. and Myers, N. (2012). Involutionary momentum: affective ecologies and the sciences of plant/insect encounters. Differences, 23(3), 74-118. https:// doi.org/10.1215/10407391-1892907

Katriel, G. (2010). Epidemics with partial immunity to reinfection. Mathematical Biosciences, 228(2), 153-159. https://doi.org/10.1016/j.mbs.2010.09.003

Kirksey, E. (2015). Emergent Ecologies. Durham: Duke University Press. https://doi.org/10.1215/9780822374800

Landecker, H. (2016). Antibiotic resistance and the biology of history. Body \& Society, 22(4), 19-52. https://doi.org/10.1177/1357034X14561341

MacPhail, T. (2014). The Viral Network: A Pathography of the H1N1 Influenza Pandemic. Ithaca: Cornell University Press.

Martin, E. (1994). Flexible Bodies: The Role of Immunity in American Culture from the Days of Polio to the Age of AIDS. Beacon Press.

M'charek, A. (2005). The Human Genome Diversity Project: An Ethnography of Scientific Practice. Cambridge: Cambridge University Press. https://doi.org/10.1017/CBO9780511489167 
M'charek, A. (2014). Race, time and folded objects: The HeLa error. Theory, Culture \& Society, 31(6), 29-56. https://doi.org/10.1177/0263276413501704

Meloni, M. (2018). A postgenomic body: Histories, genealogy, politics. Body \& Society, epub ahead of print. https://doi.org/10.1177/1357034X18785445

Mol, A. (2002). The Body Multiple: Ontology in Medical Practice. Durham: Duke University Press. https://doi.org/10.1215/9780822384151

Mutsaers, I. (2016). Immunological Discourse in Political Philosophy: Immunisation and its Discontents. London: Routledge. https://doi.org/10.4324/9781315587943

Nash, C. (2015). Genetic Geographies: The Trouble with Ancestry. Minneapolis: The University of Minnesota Press. https:// doi.org/10.5749/minnesota/9780816690633.001.0001

Newman, J. I., Shields, R. and McLeod, C. M. (2016). The MRSA epidemic and/as fluid biopolitics. Body \& Society, 22(4), 155-184. https://doi.org/10.1177/1357034X14551844

Oikkonen, V. (2018). Population Genetics and Belonging: A Cultural Analysis of Genetic Ancestry. Basingstoke: Palgrave Macmillan. https://doi.org/10.1007/978-3-319-62881-3

Ong, A. (2016). Fungible Life: Experiment in the Asian City of Life. Durham: Duke University Press. https:// doi.org/10.1215/9780822373643

Roberts, C. (2007). Messengers of Sex: Hormones, Biomedicine and Feminism. Cambridge: Cambridge University Press. https:// doi.org/10.1017/CBO9780511489174

Schrader, A. (2010). Responding to Pfiesteria piscicida (the Fish Killer). Social Studies of Science, 40(2), 275-306. https://doi.org/10.1177/0306312709344902

Takeshita, C. (2017). From mother/fetus to holobiont(s): a material feminist ontology of the pregnant body. Catalyst: Feminism, Theory, Technoscience, 3(1), 1-28.

Treichler, P. (1999). How to Have Theory in an Epidemic: Cultural Chronicles of AIDS. Durham: Duke University Press. Wald, P. (2008). Contagious: Cultures, Carriers, and the Outbreak Narrative. Durham: Duke University Press.

Zhang, X., Zhao, Y. and Neumann, A. U. (2010). Partial immunity and vaccination for influenza. Journal of Computational Biology, 17(12), 1689-1696. https://doi.org/10.1089/cmb.2009.0003

Citation: Oikkonen, V. (2018). Partial Immunities: Rethinking Communities and Belonging through Viral Memories of Influenza. Feminist Encounters: A Journal of Critical Studies in Culture and Politics, 2(2), 18. https://doi.org/10.20897/femenc/3886

Copyright (C) 2018 by Author/s and Licensed by Lectito BV, Netherlands. This is an open access article distributed under the Creative Commons Attribution License which permits unrestricted use, distribution, and reproduction in any medium, provided the original work is properly cited. 